\title{
Post-traumatic stress in patients with injury-related chronic pain participating in a multimodal pain rehabilitation program
}

This article was published in the following Dove Press journal:

Neuropsychiatric Disease and Treatment

5 March 2010

Number of times this article has been viewed

\section{Britt-Marie Stålnacke Anna Östman}

Department of Community Medicine and Rehabilitation, Umeå University, Sweden
Correspondence: Britt-Marie Stålnacke Department of Community Medicine and Rehabilitation (Rehabilitation Medicine) Bldg 9A, Umeå University Hospital, Umeå University, SE-90I 85 Umeå, Sweden Tel +46907856998 Fax +46907856990 Email brittmarie.stålnacke@rehabmed. umu.se
Aim: To investigate post-traumatic stress, pain intensity, depression, and anxiety in patients with injury-related chronic pain before and after participating in multimodal pain rehabilitation.

Methods: Twenty-eight patients, 21 women and seven men, who participated in the multimodal rehabilitation programs (special whiplash program for whiplash injuries within 1.5 years after the trauma or ordinary program) answered a set of questionnaires to assess post-traumatic stress (Impact of Event Scale [IES], pain intensity [Visual Analogue Scale (VAS)], depression, and anxiety (Hospital Anxiety and Depression Scale [HAD] before and after the programs.

Results: Both pain intensity and post-traumatic stress decreased significantly after the rehabilitation programs in comparison with before (VAS: $57.8 \pm 21.6$ vs. $67.5 \pm 21.9 ; P=0.009$, IES total score $21.8 \pm 13.2$ vs. $29.5 \pm 12.9 ; P<0.001$ ). Patients younger than 40 years reported a statistically higher level of post-traumatic stress compared with patients older than 40 years both before $(P=0.037)$ and after rehabilitation $(P=0.023)$. No statistically significant differences were found on the HAD scores.

Conclusion: The multimodal rehabilitation programs were effective in reducing both pain intensity and post-traumatic stress. The experience of higher levels of post-traumatic stress in younger persons has to be taken into account when managing patients with injury-related chronic pain

Keywords: post-traumatic, stress disorder, chronic pain, whiplash injuries

\section{Introduction}

Chronic pain, defined as pain that lasts for at least three months, ${ }^{1}$ is very common. In Sweden prevalence of chronic pain is estimated to be between $40 \%$ and $55 \% 0^{2-4}$ and accounts for the majority of long-time sick leave. ${ }^{5}$ Many factors, together or by themselves may contribute to the development of long-lasting pain, including chronic sensitization of nociceptors, derangements in the antinociceptive system and psychosomatic interaction. ${ }^{6,7}$

Most chronic pain is musculoskeletal pain, ${ }^{4}$ caused, for example by injuries such as whiplash. In Sweden, the incidence of whiplash injuries varies from 1.0 to 3.2/1000 per year. ${ }^{8,9}$ Whiplash injuries result from an acceleration-deceleration movement that indirectly transfers energy to the neck, resulting in a soft tissue injury/distortion of the neck.

A frequent cause of whiplash injuries is traffic injuries, especially rear-end collisions. Although many patients recover within a few months after an accident, a significant proportion experiences prolonged symptoms that may result in limitations in work and in leisure time. ${ }^{9,10}$ Whiplash-associated disorders (WAD) are 
clinical manifestations resulting from whiplash injuries. ${ }^{11}$ The dominating complaints are neck pain and headache, but fatigue, dizziness, irritability, anxiety, and pain arising from the shoulders and thoracic vertebral column are common symptoms. ${ }^{8,9,12}$

Patients suffering from chronic pain after accidents can also develop psychological issues, such as post-traumatic stress reactions. ${ }^{13,14}$ During the first year after a vehicle accident many patients $(10 \%-30 \%)$ are diagnosed with posttraumatic stress disorder (PTSD). ${ }^{15}$

Post-traumatic stress symptoms are characterized by three major symptom clusters: re-experiencing symptoms, avoidance symptoms, and arousal symptoms. Other frequent symptoms seen among patients with post-traumatic stress include tiredness, dizziness, irritability, sleeping disorders, and a lower ability to concentrate. ${ }^{15}$ It has been proposed that there are factors common to pain and post-traumatic stress that maintain both conditions ${ }^{14}$ and the co-occurence of chronic pain and post-traumatic stress have been documented both in patients following traffic injuries ${ }^{16}$ and in veterans. ${ }^{17-19}$ These findings may have consequences for patients who suffer from both chronic pain and post-traumatic stress as they may experience more intense pain and affective stress, greater disability and decreased life satisfaction than patients with only one of the diagnoses. ${ }^{20,21}$ Moreover the level of post-traumatic stress has been shown to be a prognostic factor for developing persistent symptoms among patients with chronic pain after an accident, especially after whiplash injuries. ${ }^{14}$ Therefore, the Swedish Society of Medicine and the Whiplash Commission task force have declared that post-traumatic stress symptoms should be diagnosed and treated early after injury in order to minimize the risk for long-lasting symptoms. ${ }^{22}$ Although studies of long-term outcome after WAD have identified risk factors such as increased age, gender and initial pain intensity ${ }^{12,23}$ the literature is inconsistent. ${ }^{24}$ However, attention have been paid to the influence of gender as a potential prognostic factor, and female gender has been associated with the development of chronic pain; ${ }^{25}$ more women than men have also been shown to suffer from post-traumatic stress symptoms. ${ }^{26}$ Moreover, patients with chronic pain and WAD do not constitute a homogenous population since several factors may coexist and interact. Due to the complexity of injury-related pain, the importance of identifying different subgroups has been proposed. ${ }^{27}$

Since chronic pain and disability are influenced by a complex interaction of physical, psychological, and social factors, the biopsychosocial model has been adopted in multimodal pain rehabilitation interventions. ${ }^{28,29}$ These are currently based on cognitive - behavioral principles. A number of studies have shown positive effects of multidisciplinary treatments and multimodal rehabilitation of chronic pain. ${ }^{30}$

As part of regular procedures at the Pain Rehabilitation Clinic at the Umeå University Hospital, patients complete questionnaires that are included in the Swedish National Quality Registry for Pain Rehabilitation (NRS) after participating in the rehabilitation programs. However, there is no systematic follow-up of post-traumatic stress symptoms.

The aims of this pilot-study were therefore: (i) to investigate the occurrence and levels of post-traumatic stress among patients before and after participating in pain rehabilitation programmes; (ii) to assess relationships between the level of post-traumatic stress and pain intensity, anxiety, depression, activity level, and life satisfaction; and (iii) to examine any possible difference in post-traumatic stress between different age groups, younger, and older patients.

\section{Methods}

\section{Patients and procedure}

This pilot study includes 28 patients, 21 women and seven men, mean age 36 years \pm (range: $21-53$ years), who were admitted for rehabilitation to the Pain Rehabilitation Clinic at the University Hospital, Umeå, Sweden because of chronic musculoskeletal pain caused by an injury sustained between April 2006 to March 2007. Whiplash injury caused the trauma in 20 patients and other types of accidents (such as falling or being hit by a tree) caused the trauma in eight patients. Three patients had an additional accident within four years before the actual trauma. About $50 \%$ of the patients were on full-time sick leave when they began the rehabilitation program, $17.9 \%$ were on part-time sick leave, and 28.6\% were working or studying. In the referrals from the primary care physicians, only pain symptoms (no post-traumatic stress-related symptoms) were described. Most patients had an upper secondary school education (20 patients), some had a university education (seven patients), and one had a compulsory school education. To compare age groups, patients were divided into "younger than 40 years" (10 patients) and "older than 40 years" (12 patients).

Eighteen patients $(64.3 \%)$ participated in a special program (WAD program) for patients with whiplash injuries within 1.5 years of their accident and 10 patients participated in a regular rehabilitation program for patients with chronic pain of other origins. Both rehabilitation programs were based on cognitive-behavioral principles and 
consisted of daily sessions six hours a day for five weeks. Each patient received a personal schedule and had their own team that consisted of a clinical psychologist trained in cognitive - behavior skills, an occupational therapist, a physiotherapist, a specialist physician in rehabilitation medicine, and a social worker. The whiplash program was more focused on the whiplash injury, but both programs included components of education about chronic pain, about bodily and psychological reactions to pain, and about pain management. Both programs included activity exercises, psychoeducational group therapy that focused on coping strategies and assertiveness training, post-traumatic stress, relaxation and body awareness training.

Before and after participating in the rehabilitation programs patients completed questionnaires that are included in the NRS. The questionnaires ask the patients to estimate their level of discomfort and pain using several instruments: the Visual Analogue Scale (VAS) ${ }^{31}$ for pain intensity; the Hospital Anxiety and Depression Scale (HAD) ${ }^{32}$ for anxiety and depression; the Disability Rating Index (DRI) ${ }^{33}$ for activity level; and the Life Satisfaction checklist (LiSat-11) $)^{34}$ for life satisfaction. To guarantee quality and to evaluate rehabilitation work, the answers were registered in the NRS. Data about the patients participating in the study were collected from the NRS. Other information, such as sick leave, the cause of accident and which programs patients had participated in were collected from hospital records.

\section{Instruments}

\section{Post-traumatic stress}

The Impact of Event Scale (IES) ${ }^{35}$ measures the level of post-traumatic stress. The IES, a screening tool that includes 15 statements about particular difficulties associated with stressful life events, asks patients to rate $(0=$ never, $1=$ seldom, $3=$ sometimes, $5=$ often) the degree to which a statement describes their previous week. The total score of the 15 statements is 75 and the score is divided into four grades or stress reactions: sub-clinical (0-8), mild (9-25), moderate (26-43), and severe (44-75). Seven statements address intrusive symptoms such as sleeping difficulties because of thinking about the accident and having unexpected sudden flashbacks of the accident. Eight statements address avoidance symptoms, such as avoiding things or situations that could be a reminder of the accident. The total IES scale includes the intrusion and the avoidance subscales. The IES has been validated and found to be a useful measure of stress reactions in a large number of populations exposed to various traumatic experiences, including road traffic accidents and have been used in previous studies regarding whiplash injuries ${ }^{36,37}$

\section{Pain intensity}

The VAS ${ }^{31}$ is an instrument that measures pain intensity. The patients mark their experienced pain on a $100 \mathrm{~mm}$ straight line, where 0 means "no pain" and 100 "worst pain imaginable".

\section{Depression and anxiety}

The HAD ${ }^{32}$ is an instrument that is used to find and to estimate the level of anxiety and depression. It consists of seven questions rating anxiety and seven questions rating depression. Each question gives a score from 0 to 3 points. If the patient scores 8-10 points in one category it is considered a limit value for mild to moderate symptoms. More than 10 points indicates severe symptoms.

\section{Level of activity}

The Disability Rating Index (DRI) ${ }^{33}$ comprises 12 questions about ordinary activities, for example walking, running, sitting, standing, carrying, lifting, making the bed etc. The patients estimate their activity level on a 0 to $100-\mathrm{mm}$ visual analogue scale, where 0 means "manages without difficulty" and 100 means "does not manage at all".

\section{Life satisfaction}

The Life Satisfaction checklist (LiSat-11) ${ }^{34}$ questionnaire estimates a patient's level of life satisfaction in 11 areas: life as a whole, profession/situation on the labour market, economy, leisure time, contacts with familiar and friends, sexual life, activities of daily living, family life, partner, somatic health and psychological health. Levels of satisfaction are estimated on a 6-point response scale, from "very dissatisfied" to "very satisfied".

\section{Statistics}

Statistical analysis was performed with Statistic Package for Social Sciences software (v. 17.0 for Windows; SPSS Inc., Chicago, IL). Data are reported as means \pm standard deviations. For comparison between before and after rehab programs Wilcoxon signed-ranks-test was used. Comparisons between men and women and different age groups were made using the Mann-Whitney $U$-test. For calculating the correlation between IES and VAS, DRI, HAD and LiSat-11 before and after the rehabilitation program, Spearman's correlation test was used. Statistical significant level was set at $P<0.05$. The study was approved by the ethics committee of Umeå University. 
Table I Before rehabilitation

\begin{tabular}{llllll}
\hline & All patients $(\mathbf{n}=\mathbf{2 8})$ & Men $(\mathbf{n}=\mathbf{7})$ & Women $(\mathbf{n}=\mathbf{2 1})$ & $<\mathbf{4 0}$ years $(\mathbf{n}=\mathbf{I 6})$ & $\geq \mathbf{4 0}$ years $(\mathbf{n}=\mathbf{I 2})$ \\
\hline IES total score & $29.5 \pm 12.9$ & $26.1 \pm 9.3$ & $30.6 \pm 13.9$ & $33.8 \pm 10.9$ & $23.7 \pm 13.6$ \\
Intrusion & $16.1 \pm 6.8$ & $16.0 \pm 4.6$ & $16.2 \pm 7.5$ & $18.4 \pm 6.4$ & $13.2 \pm 6.5$ \\
Avoidance & $13.4 \pm 8.9$ & $10.1 \pm 5.9$ & $14.4 \pm 9.6$ & $15.4 \pm 8.8$ & $10.6 \pm 8.7$ \\
VAS & $67.5 \pm 21.9$ & $57.1 \pm 24.0$ & $70.9 \pm 20.7$ & $70.7 \pm 23.2$ & $63.2 \pm 20.3$ \\
HAD anxiety & $9.26 \pm 4.2$ & $8.4 \pm 4.6$ & $9.5 \pm 4.2$ & $10.3 \pm 4.2$ & $8.0 \pm 4.1$ \\
HAD depression & $7.5 \pm 4.1$ & $6.1 \pm 3.9$ & $8.0 \pm 4.1$ & $8.0 \pm 4.1$ & $6.9 \pm 4.2$ \\
\hline
\end{tabular}

Abbreviations: IES, Impact of Event scale; HAD, Hospital Anxiety and Depression Scale;VAS, Visual Analogue Scale.

\section{Results}

\section{Post-traumatic stress}

Post-traumatic stress was assessed using the IES. In all patients the number of post-traumatic stress- related symptoms decreased significantly $(P=0.014)$ after the rehabilitation programs $(8.9 \pm 4.5)$ compared to before the rehabilitation programs $(11.0 \pm 3.5)$. In all patients, posttraumatic stress scores also decreased significantly after participating in rehabilitation programs with respect to the total IES scale (before, $29.5 \pm 1.9$; after, $21.8 \pm 13.2 ; P<0.001$ ) as well as the subscale intrusion (before, $16.1 \pm 6.8$; after; $11.4 \pm 7.5 ; P<0.001$ ) and avoidance (before, $13.4 \pm 8.9$; after, $10.4 \pm 8.5 ; P=0.031$ ) compared to the post-traumatic stress levels before the program (Tables 1, 3; Figure 1).

The levels of post-traumatic stress are shown in Tables 2 and 3; according to the subclassification by Kongsted and colleagues, ${ }^{36}$ mild stress response was observed in 39.2\% before rehabilitation (subclinical and mild stress reactions) and distinct stress response was present in $60.7 \%$ (moderate and severe stress reactions). After rehabilitation $64.3 \%$ reported mild stress response (subclinical and mild stress reactions) and distinct stress response was reported by $35.7 \%$.

\section{Post-traumatic stress in gender and age groups}

The IES scores with respect to gender are shown in Tables 2 and 3 . There was no statistically significant difference between men and women before and after participating in rehabilitation programs concerning the scores on the total IES scale (men before, $26.1 \pm 9.3$; women before, $30.6 \pm 13.9 ; P=0.376$; men after, $17.4 \pm 13.5$; women after, $23.2 \pm 13.1 ; P=0.249$ ) or the subscales intrusion (men before, $16.0 \pm 4.6$; women before, $16.2 \pm 7.5 ; P=0.979$; men after, $10.7 \pm 8.0$; women after, 11.6 $\pm 7.5 ; P=0.796$ ), and avoidance (men before, $10.1 \pm 5.9$; women before, $14.4 \pm 9.6 ; P=0.321$; men after, $6.7 \pm 6.5$; women after, $11.6 \pm 8.8 ; P=0.228)$.

For comparison between two age groups, patients were divided into the following groups: "younger than 40 years" $(\mathrm{n}=16)$ and "older than 40 years" $(\mathrm{n}=12)$. The age group younger than 40 years reported a statistically significantly higher scores of post-traumatic stress compared with patients older than 40 years before rehabilitation programs on the total IES scale (younger, $33.8 \pm 10.9$; older, $23.7 \pm 13.6$; $P=0.037$ ) and the subscale intrusion (younger, $18.4 \pm 6.4$; older, 13.2 $\pm 6.5 ; P=0.042$ ) (Table 1 ), as well as after rehabilitation programs on the total IES scale (younger, $26.3 \pm 0.8$; older, $15.7 \pm 14.2 ; P=0.023)$ and the subscale intrusion (younger, $14.1 \pm 7.4$; older, $7.7 \pm 6.1 ; P=0.029$ ) (Table 3). No significant difference was found between the age groups on the subscale avoidance before rehabilitation (younger, 15.4 \pm 8.8 ; older, 10.6 $\pm 8.7 ; P=0.189$ ) (Table 1) or after rehabilitation (younger, 12.2 \pm 8.0 ; older, $8.0 \pm 8.8$; $P=0.133$ ) (Table 3 ). The levels of post-traumatic stress with respect to genders and age-groups are shown in Tables 2 and 4.

Table 2 Level of stress reaction before rehabilitation

\begin{tabular}{lclcll}
\hline & All patients $(\mathrm{n}=\mathbf{2 8})(\%)$ & Men $(\mathrm{n}=\mathbf{7})(\%)$ & Women $(\mathrm{n}=\mathbf{2 1})(\%)$ & $<\mathbf{4 0}$ years $(\mathrm{n}=\mathbf{1 6})(\%)$ & $\geq \mathbf{4 0}$ years $(\mathrm{n}=\mathbf{I 2})(\%)$ \\
\hline Subclinical & 7.1 & & 9.5 & & 16.7 \\
Mild & 32.1 & 42.9 & 28.6 & 25.0 & 41.7 \\
Moderate & 53.6 & 57.1 & 52.4 & 68.8 & 33.3 \\
Severe & 7.1 & & 9.5 & 6.3 & 8.3 \\
\hline
\end{tabular}




\section{IES total score}

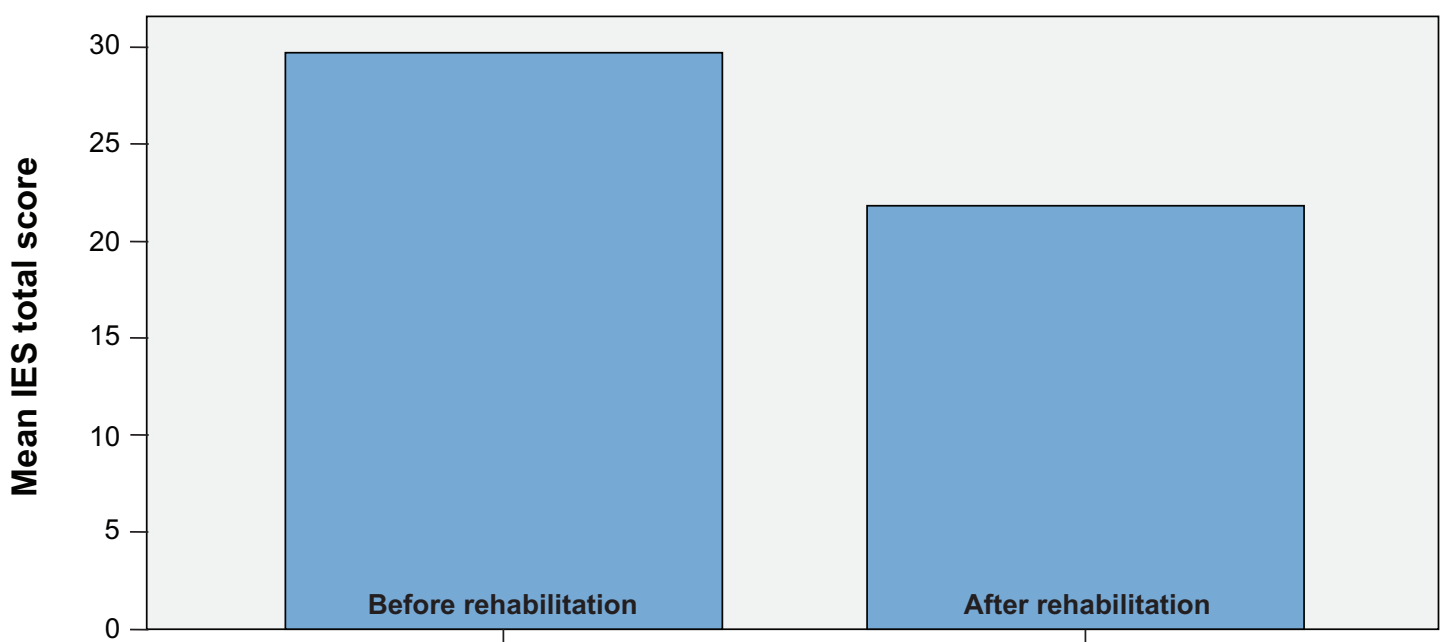

Figure I Total IES score before (29.5 \pm 12.9; range: I-57) and after (2I.8 \pm I3.2; range: I-49) in all patients $(n=28)$.

Abbreviation: IES, Impact of Event scale.

\section{Comparison of post-traumatic stress between the two rehabilitation programs}

When comparing patients who participated in the WAD program with patients participating in the regular rehabilitation program before and after rehabilitation no statistically significant differences were found concerning the number of post-traumatic stress-related symptoms (before, $P=0.942$; after, $P=0.322$ ), the level of post-traumatic stress on the total IES scale (before, $P=0.456$; after, $P=0.113$ ) or on the IES subscales (intrusion before, $P=0.203$; after, $P=0.230$; avoidance before, $P=0.581$; after, $P=0.229$ ).

\section{Pain intensity, disability, depression, anxiety, and life satisfaction}

Pain intensity on the VAS was significantly decreased $(P=0.009)$ for all patients after the rehabilitation program
$(57.8 \pm 21.6)$ (Table 3$)$ in comparison with before $(67.5 \pm 21.9)$ (Table 1). No statistically significant differences were found when comparing the scores of the HAD anxiety and depression scales (Tables 1 and 3), the total DRI scale, and the total LiSat-11 scale before and after the rehabilitation program $(P>0.05)$. Some of the separate items showed a statistically significant improvement after the rehabilitation program in comparison with before the program: light work on the DRI $(P=0.007)$ and psychological health on the LiSat-11 $(P=0.011)$.

\section{Correlations}

Statistically significant correlations were shown between the scores of IES and HAD anxiety, both before and after rehabilitation programs (before, $r=0.570, P=0.002$; after, $r=0.637, P<0.001)$. The IES score after rehabilitation was also statistically significantly correlated to the HAD depression scores $(r=0.399, P=0.036)$; no such correlation

Table 3 After rehabilitation

\begin{tabular}{|c|c|c|c|c|c|}
\hline & All patients $(n=28)$ & Men $(n=7)$ & Women $(n=2 I)$ & $<40$ years $(n=16)$ & $\geq 40$ years $(n=12)$ \\
\hline IES total score & $21.8 \pm 13.2$ & $17.4 \pm 13.5$ & $23.2 \pm 13.1$ & $26.3 \pm 0.8$ & $15.7 \pm 14.2$ \\
\hline Intrusion & $1 \mathrm{I} .4 \pm 7.5$ & $10.7 \pm 8.0$ & $11.6 \pm 7.5$ & $|4| \pm 7.4$. & $7.7 \pm 6.1$ \\
\hline Avoidance & $10.4 \pm 8.5$ & $6.7 \pm 6.5$ & $11.6 \pm 8.8$ & $12.2 \pm 8.0$ & $8.0 \pm 8.8$ \\
\hline VAS & $57.8 \pm 21.6$ & $57.6 \pm 27.3$ & $57.9 \pm 20.1$ & $60.6 \pm 23.7$ & $54.2 \pm 18.7$ \\
\hline HAD anxiety & $8.2 \pm 3.9$ & $7.7 \pm 3.5$ & $8.3 \pm 4.1$ & $9.8 \pm 3.9$ & $6.0 \pm 2.8$ \\
\hline HAD depression & $7.1 \pm 3.7$ & $5.7 \pm 3.1$ & $7.6 \pm 3.9$ & $7.4 \pm 4.2$ & $6.7 \pm 3.3$ \\
\hline
\end{tabular}

Abbreviations: IES, Impact of Event scale; HAD, Hospital Anxiety and Depression Scale;VAS, Visual Analogue Scale. 
Table 4 Level of stress reaction after rehabilitation

\begin{tabular}{llllll}
\hline & All patients $(\mathbf{n}=\mathbf{2 8})(\%)$ & Men $(\mathbf{n}=\mathbf{7})(\%)$ & Women $(\mathbf{n}=\mathbf{2 1})(\%)$ & $<\mathbf{4 0}$ years $(\mathbf{n}=\mathbf{1 6})(\%)$ & $\geq \mathbf{4 0}$ years $(\mathbf{n}=\mathbf{~ I 2 )}(\mathbf{\%})$ \\
\hline Sub clinical & 17.9 & 14.3 & 19.0 & 6.3 & 33.3 \\
Mild & 46.4 & 71.4 & 38.1 & 43.8 & 50.0 \\
Moderate & 32.1 & 14.3 & 38.1 & 50.0 & 8.3 \\
Severe & 3.6 & & 4.8 & & 8.3 \\
\hline
\end{tabular}

was found before rehabilitation. No statistical significant correlation was found between the scores of IES and the VAS, DRI, and LiSat-11 scores.

\section{Discussion}

This pilot study shows that the level of post-traumatic stress as well as the number of post-traumatic stress-related symptoms and pain intensity significantly decreased in patients after participating in the multimodal pain rehabilitation programs. These programs include multidisciplinary treatment and are based on cognitive-behavioral principles. The aim is to reduce disability in patients with chronic pain and both physiological and psychological factors are focused on. In the literature of pain rehabilitation a number of studies have shown that multidisciplinary interventions are more effective than nondisciplinary treatments. ${ }^{30}$ Several studies have investigated post-traumatic stress after vehicle accidents $^{38}$ and interventions that include cognitive-behavioral treatment have also been shown to decrease post-traumatic stress. ${ }^{39-41}$ In a randomized controlled study, Blanchard and colleagues ${ }^{42}$ studied different methods of treatments for PTSD in patients who had survived a vehicle accident (on an average of 13 months earlier). The authors found that cognitive therapy, in comparison with psychotherapy support or being placed on a waiting list, more effective decreased post-traumatic stress. In their study, the significant improvement in PTSD was also sustained at the follow-up three months after the treatment. In a recent study by Otis and colleagues ${ }^{19}$ of veterans with chronic pain and PTSD, a combination of cognitive processing therapy and cognitive-behavioral therapy for an integrative treatment of both disorders showed positive results. These findings may have implications in the future for treatment design of patients with injury-related chronic pain.

In the present study, the IES was used to assess posttraumatic stress. This instrument has been used in previous studies of post-traumatic stress in vehicle related accidents mostly in whiplash injuries. ${ }^{36-38,43}$ The levels of post-traumatic stress with $60.7 \%$ of patients suffering from moderate to severe stress before rehabilitation were clearly higher than previously reported early after injury $(13 \%)^{36}$ but also higher comparing with previous results from our clinic (48\%). ${ }^{44}$ However, the post-traumatic stress levels decreased noticeably during the rehabilitation programs; only $35.7 \%$ reported moderate to severe stress after rehabilitation.

Moreover, when time since trauma was compared between the two groups participating in rehabilitation programs, there was a considerable difference from the time of the accident to when the patients began the two different rehabilitation programs; approximately 1.5 years for the patients in the WAD program compared with approximately five years for the patients in the general rehabilitation program. Despite the difference in time, there was no significant difference between the level of post-traumatic stress in the patients participating in the WAD program compared with patients in the general rehabilitation program, neither before nor after the programs. However, to optimize the results it seems obvious that patients should have been offered rehabilitation earlier. Recently, Sullivan and colleagues pointed out the importance of early adequate management of pain symptoms and disability in whiplash patients to reduce the severity of post-traumatic stress symptoms. ${ }^{45}$ The Swedish Society of Medicine and the Whiplash Commission task force $^{22}$ have called attention to the importance of observing and treating PTSD in patients with whiplash injuries in order to minimize the risk for long-lasting symptoms. Concerning the patients in both the WAD and the general pain rehabilitation programs, no post-traumatic stress-related symptoms were described in the referrals prepared by the primary care physicians who had referred the patients. This indicates that these symptoms had not been observed earlier and this may have had an effect on the development of the patients' chronic pain symptoms.

In this study, the patients in the group younger than 40 years had a greater number of and more severe posttraumatic stress symptoms in comparison with the group of patients older than 40 years. Earlier studies of post-traumatic stress among individuals in different age groups have shown different results. For example, older individuals have been reported to experience less post-traumatic stress than younger, which may be because older individuals may work through traumatic episodes much earlier than younger individuals, 
an approach that may enhance their ability to cope with new traumas. ${ }^{46}$ Not only has it been shown that higher age could imply a higher risk of developing post-traumatic stress symptoms,${ }^{47}$ but at the same time it also has been reported that no difference concerning post-traumatic stress measured with the instrument IES could be found between younger, older and middle-aged individuals. ${ }^{48}$

There was no significant difference in experienced posttraumatic stress symptoms between men and women in the present study. Other studies with a greater number of patients have shown that women suffer from more post-traumatic stress than men. ${ }^{26,49}$ It is possible that differences between genders concerning the presence of post-traumatic stress among patients with chronic pain are due to the study populations.

The correlation between IES and HAD anxiety was significant, which shows a clear relationship between the level of post-traumatic stress symptoms and anxiety. This link is also described in earlier literature and may be caused by an interaction between these symptoms. ${ }^{50}$

In the present study, patients rated pain intensity on VAS. The mean scores were high in compared to previous studies of whiplash patients and patients with chronic pain $^{25,38,44}$ and clearly higher than reported by Roth and colleagues $^{16}$ of patients with injury-related chronic pain referred to a pain rehabilitation program. However, in contrast to some previous studies, no significant association was found between pain intensity and post-traumatic stress. ${ }^{16,44}$ These findings may be due to the small study population in our study.

The present study has several limitations. First, despite the fact that a small group of patients participated in this pilot study and that there is no long-term follow-up, the decrease of post-traumatic stress and pain intensity during the multimodal rehabilitation programs is a promising result. With regard to future research, it would be useful to investigate a larger study population with a long time follow-up. In our pilot study, we did not include a control group. Future studies could use waiting list controls and should focus on the long-term effects of rehabilitation programs on pain and post-traumatic stress. Moreover, since the population was small and several instruments were included, we cannot rule out the possibility of type I and type II errors.

In conclusion, the multimodal rehabilitation program was effective in reducing both pain intensity and post-traumatic stress. The experience of higher levels of post-traumatic stress in younger persons has to be taken into account when managing patients with injury-related chronic pain. Continuously using the IES questionnaires, in addition to the ordinary instruments at our clinic for patients with chronic pain, could lead to increased knowledge and a possibility to detect post-traumatic stress. This could lead to a modified strategy of treatment and rehabilitation.

\section{Disclosures}

The authors report no conflicts of interest in this work.

\section{References}

1. Pain terms: A list of definitions and notes on usage. Recommended by the IASP Subcommittee on Taxonomy. Pain. 1979;6:249-252.

2. Brattberg G, Thorslund M, Wikman A. The prevalence of pain in a general population. The results of a postal survey in a county of Sweden. Pain. 1989;37(2):215-222.

3. Andersson HI, Ejlertsson G, Leden I, Rosenberg C. Chronic pain in a geographically defined general population: studies of differences in age, gender, social class, and pain localization. Clin J Pain. 1993;9(3): 174-182.

4. Gerdle B, Bjork J, Henriksson C, Bengtsson A. Prevalence of current and chronic pain and their influences upon work and healthcare-seeking: a population study. $J$ Rheumatol. 2004;31(7):1399-1406.

5. Lundberg D, Axelsson S, Boive J, et al. Metoder för behandling av långvarig smärta. En systematisk litteraturöversikt. Stockholm, Sweden: The Swedish Council on Technology Assessment in Health Care; 2006.

6. Mense S. The pathogenesis of muscle pain. Curr Pain Headache Rep. 2003;7(6):419-425.

7. Sullivan MJ, Rodgers WM, Kirsch I. Catastrophizing, depression and expectancies for pain and emotional distress. Pain. 2001;91(1-2): $147-154$.

8. Herrstrom P, Lannerbro-Geijer G, Hogstedt B. Whiplash injuries from car accidents in a Swedish middle-sized town during 1993-1995. Scand J Prim Health Care. 2000;18(3):154-158.

9. Sterner Y, Toolanen G, Gerdle B, Hildingsson C. The incidence of whiplash trauma and the effects of different factors on recovery. J Spinal Disord Tech. 2003;16(2):195-199.

10. Spitzer WO, Skovron ML, Salmi LR, et al. Scientific monograph of the Quebec Task Force on Whiplash-Associated Disorders: redefining "whiplash" and its management. Spine. 1995;20(8 Suppl):1S-73S.

11. Barnsley L, Lord S, Bogduk N. Whiplash injury. Pain. 1994;58(3): 283-307.

12. Radanov BP, di Stefano G, Schnidrig A, Ballinari P. Role of psychosocial stress in recovery from common whiplash. Lancet. 1991;338(8769):712-715.

13. Kuch K, Cox BJ, Evans RJ. Posttraumatic stress disorder and motor vehicle accidents: a multidisciplinary overview. Can J Psychiatry. 1996;41(7):429-434.

14. Sharp TJ, Harvey AG. Chronic pain and posttraumatic stress disorder: mutual maintenance? Clin Psychol Rev. 2001;21(6):857-877.

15. Mayou R, Bryant B. Psychiatry of whiplash neck injury. Br J Psychiatry. 2002;180:441-448.

16. Roth RS, Geisser ME, Bates R. The relation of post-traumatic stress symptoms to depression and pain in patients with accident-related chronic pain. J Pain. 2008;9(7):588-596.

17. Shipherd JC, Keyes M, Jovanovic T, et al. Veterans seeking treatment for posttraumatic stress disorder: what about comorbid chronic pain? J Rehabil Res Dev. 2007;44(2):153-166.

18. Otis JD, Keane TM, Kerns RD. An examination of the relationship between chronic pain and post-traumatic stress disorder. $J$ Rehabil Res Dev. 2003;40(5):397-405.

19. Otis JD, Keane TM, Kerns RD, Monson C, Scioli E. The development of an integrated treatment for veterans with comorbid chronic pain and posttraumatic stress disorder. Pain Med. 2009;10(7):1300-1311. 
20. Turk DC, Okifuji A. Perception of traumatic onset, compensation status, and physical findings: impact on pain severity, emotional distress, and disability in chronic pain patients. J Behav Med. 1996;19(5): 435-453.

21. Sherman JJ, Turk DC, Okifuji A. Prevalence and impact of posttraumatic stress disorder-like symptoms on patients with fibromyalgia syndrome. Clin J Pain. 2000;16(2):127-134.

22. Jansen GB, Edlund C, Grane P, et al. Whiplash injuries: diagnosis and early management. The Swedish Society of Medicine and the Whiplash Commission Medical Task Force. Eur Spine J. 2008;17(Suppl 3): S355-S417.

23. Kyhlback M, Thierfelder T, Soderlund A. Prognostic factors in whiplashassociated disorders. Int J Rehabil Res. 2002;25(3):181-187.

24. Williamson E, Williams M, Gates S, Lamb SE. A systematic literature review of psychological factors and the development of late whiplash syndrome. Pain. 2008;135(1-2):20-30.

25. Berglund A, Bodin L, Jensen I, Wiklund A, Alfredsson L. The influence of prognostic factors on neck pain intensity, disability, anxiety and depression over a 2-year period in subjects with acute whiplash injury. Pain. 2006;125(3):244-256.

26. Ursano RJ, Fullerton CS, Epstein RS, et al. Acute and chronic posttraumatic stress disorder in motor vehicle accident victims. Am J Psychiatry. 1999;156(4):589-595.

27. Sterner Y, Gerdle B. Acute and chronic whiplash disorders-a review. $J$ Rehabil Med. 2004;36(5):193-209; quiz 210.

28. Gatchel RJ, Peng YB, Peters ML, Fuchs PN, Turk DC. The biopsychosocial approach to chronic pain: scientific advances and future directions. Psychol Bull. 2007;133(4):581-624.

29. McLean SA, Clauw DJ, Abelson JL, Liberzon I. The development of persistent pain and psychological morbidity after motor vehicle collision: integrating the potential role of stress response systems into a biopsychosocial model. Psychosom Med. 2005;67(5):783-790.

30. Scascighini L, Toma V, Dober-Spielmann S, Sprott H. Multidisciplinary treatment for chronic pain: a systematic review of interventions and outcomes. Rheumatology. 2008;47(5):670-678.

31. Scrimshaw SV, Maher C. Responsiveness of visual analogue and McGill pain scale measures. J Manipulative Physiol Ther. 2001;24(8): 501-504.

32. Zigmond AS, Snaith RP. The hospital anxiety and depression scale. Acta Psychiatr Scand. 1983;67(6):361-370.

33. Salen BA, Spangfort EV, Nygren AL, Nordemar R. The Disability Rating Index: an instrument for the assessment of disability in clinical settings. J Clin Epidemiol. 1994;47(12):1423-1435.

34. Fugl-Meyer AR, Melin R, Fugl-Meyer KS. Life satisfaction in 18- to 64-year-old Swedes: in relation to gender, age, partner and immigrant status. J Rehabil Med. 2002;34(5):239-246.

35. Horowitz M, Wilner N, Alvarez W. Impact of Event Scale: a measure of subjective stress. Psychosom Med. 1979;41(3):209-218.
36. Kongsted A, Bendix T, Qerama E, et al. Acute stress response and recovery after whiplash injuries. A one-year prospective study. Eur $J$ Pain. 2008;12(4):455-463.

37. Sterling M, Kenardy J, Jull G, Vicenzino B. The development of psychological changes following whiplash injury. Pain. 2003;106(3): 481-489.

38. Shipherd JC, Beck JG, Hamblen JL, Lackner JM, Freeman JB. A preliminary examination of treatment for posttraumatic stress disorder in chronic pain patients: a case study. J Trauma Stress. 2003;16(5): 451-457.

39. Taylor S, Fedoroff IC, Koch WJ, Thordarson DS, Fecteau G, Nicki RM. Posttraumatic stress disorder arising after road traffic collisions: patterns of response to cognitive-behavior therapy. J Consult Clin Psychol. 2001;69(3):541-551

40. Jaspers JP. Whiplash and post-traumatic stress disorder. Disabil Rehabil. 1998;20(11):397-404.

41. Palyo SA, Beck JG. Post-traumatic stress disorder symptoms, pain, and perceived life control: associations with psychosocial and physical functioning. Pain. 2005;117(1-2):121-127.

42. Blanchard EB, Hickling EJ, Devineni T, et al. A controlled evaluation of cognitive behavioural therapy for posttraumatic stress in motor vehicle accident survivors. Behav Res Ther. 2003;41(1):79-96.

43. Stålnacke BM. Relationship between symptoms and psychological factors five years after whiplash injury. J Rehabil Med. 2009;41(5): 353-359.

44. Åhman S, Stålnacke BM. Post-traumatic stress, depression, and anxiety in patients with injury-related chronic pain: A pilot study. Neuropsychiatr Dis Treat. 2008;4(6):1245-1249.

45. Sullivan MJ, Thibault P, Simmonds MJ, Milioto M, Cantin AP, Velly AM. Pain, perceived injustice and the persistence of posttraumatic stress symptoms during the course of rehabilitation for whiplash injuries. Pain. 2009;145(3):325-331.

46. Lyons J. Strategies for assessing the potential for positive adjustment following trauma. J Traumatic Stress. 1991;4:93-111.

47. Lyons JM, McClendon OB. Changes in PTSD symptomatology as a function of aging. Nova-Psy Newslett. 1990;8:13-18.

48. Chung MC, Werrett J, Easthope Y, Farmer S. Coping with posttraumatic stress: young, middle-aged and elderly comparisons. Int $J$ Geriatr Psychiatry. 2004;19(4):333-343.

49. Fullerton CS, Ursano RJ, Epstein RS, et al. Gender differences in posttraumatic stress disorder after motor vehicle accidents. Am J Psychiatry. 2001;158(9):1486-1491.

50. Beck JG, Grant DM, Read JP, et al. The Impact of Event Scale-Revised: Psychometric properties in a sample of motor vehicle accident survivors. J Anxiety Disord. 2008;22(2):187-198.
Neuropsychiatric Disease and Treatment

\section{Publish your work in this journal}

Neuropsychiatric Disease and Treatment is an international, peerreviewed journal of clinical therapeutics and pharmacology focusing on concise rapid reporting of clinical or pre-clinical studies on a range of neuropsychiatric and neurological disorders. This journal is indexed on PubMed Central, the 'PsycINFO' database and CAS, and is the official
Dovepress

journal of The International Neuropsychiatric Association (INA). The manuscript management system is completely online and includes a very quick and fair peer-review system, which is all easy to use. Visit http://www.dovepress.com/testimonials.php to read real quotes from published authors. 